\title{
Ethical Issues and Management of Fetal Hemolytic Anemia Caused by Anti-Rh17 in a Multipara with Rare -D- Phenotype
}

\author{
Patrick P. Torreiter ${ }^{\mathrm{a}} \quad$ Susanne Macher ${ }^{\mathrm{a}} \quad$ Eva-Maria Matzhold ${ }^{\mathrm{a}}$ Bernhard Resch $^{\mathrm{b}}$ \\ Philipp Klaritsch ${ }^{c}$ Günther F. Körmöczid ${ }^{d}$ Helene Polin $^{\mathrm{e}} \quad$ Leopold Neuhold $^{f}$ \\ Marlies Schönbacher ${ }^{d}$ Peter Schlenke $^{a}$ Thomas Wagner ${ }^{a}$ \\ a Department of Blood Group Serology and Transfusion Medicine, Medical University of Graz, Graz, Austria; \\ ${ }^{\mathrm{b}}$ Divison of Neonatology, Medical University of Graz, Graz, Austria; ' Department of Obstetrics and Gynecology, \\ Medical University of Graz, Graz, Austria; ${ }^{d}$ Department of Blood Group Serology and Transfusion Medicine, Medical \\ University of Vienna, Vienna, Austria; ${ }^{e}$ Red Cross Transfusion Service of Upper Austria, Linz, Austria; ${ }^{f}$ Institute of \\ Ethics and Sociology, University of Graz, Graz, Austria
}

\section{Keywords}

Hemolytic anemia · Anti-Rh17 (anti-Hr0) - Maternal alloimmunization $\cdot$ Hyperbilirubinemia $\cdot$ Medical ethics

\begin{abstract}
Background: The development of allo-anti-Rh17 (anti-HrO) in a -D- phenotype whose red blood cells (RBCs) lack CcEe antigens is most likely triggered by transfusion, transplantation, or pregnancy. Gene conversion is the predominating factor in generating RHD-CE-D and RHCE-D-CE hybrids like -D-. Methods: We report here immunohematological and obstetrical data from 2 of the 5 pregnancies of a 24-year-old woman presenting with the -D- phenotype with anti-Rh17. Blood group typing, antibody screening, antibody differentiation, direct antiglobulin test (DAT), and antibody titers were performed by routine gel technology and tube testing. Additionally, molecular genetic analysis was performed. Fetal surveillance was done by sonographic evaluation of the fetal middle cerebral artery peak systolic velocity (MCA-PSV). Results: Blood group typing showed O, C-c-D+E-e- and the DAT was negative. DNA sequencing revealed homozygosity for an RHCE-D(3-9)-CE null allele. Anti-Rh17 titers in the fourth pregnancy remained between $1: 8$ and $1: 128$, and no signs for a fetal anemia were observed. However, in the fifth
\end{abstract}

pregnancy, the antibody titers increased up to 1:4,096. Signs of moderate fetal anemia were detected and cesarean section was performed at $34+6$ weeks of gestation. The newborn presented with hemolytic anemia (cord blood hemoglobin $[\mathrm{Hb}]=8.5 \mathrm{mg} / \mathrm{dL}$ ). She received 2 compatible (small) packed RBC concentrates, phototherapy, and intravenous immunoglobulins. Conclusion: Our case shows that the risk for hemolytic complications increases with the number of pregnancies of sensitized women. Only people who also lack CcEe antigens are compatible as donors. The role of such rare donors as lifesavers, their freedom, and voluntariness conflict with the urgent need for compatible blood.

(c) 2021 S. Karger AG, Basel

\section{Introduction}

The Rh blood group belongs to the most polymorphic blood group system in humans. Nevertheless, the RHD and RHCE genes encoding the antigens $\mathrm{D}$ and CcEe, respectively, have the same genomic organization including 10 exons, with an overall homology of $93.8 \%$. Genomic rearrangements between closely linked homologous genes lead to many examples of variant Rh phenotypes. Gene conversion is the main factor in generating RHD- 
CE-D and RHCE-D-CE hybrids. The molecular basis of -D- phenotypes is mainly caused by homozygosity for RHCE-D-CE hybrids. The prevalence of the -D- phenotype ranges between 0.0005 in Sweden and 0.005 in American Hispanics [1]. Such individuals lack any expression of CcEe antigens on their red blood cells (RBCs). However, they usually exhibit exalted D antigen expression. Despite the rarity of this variant, it has been described in different ethnic groups, especially in those with high consanguinity rates. After transfusion, transplantation, or pregnancy, these individuals may become sensitized to the high-frequency antigen Rh17, resulting in anti-Rh17 which reacts with $\mathrm{RBCs}$ of all common $\mathrm{Rh}$ phenotypes [1]. The management of pregnancies with anti-Rh17 is challenging, as maternal anti-RH17 may cause mild to severe hemolytic reactions including hemolytic disease of the fetus or the newborn (HDFN) [2-5].

Here, we report the immunohematological and obstetrical history of a 24 -year-old multipara of Iraqi origin, homozygous for $-\mathrm{D}-$ with anti-Rh17. Due to the extreme rarity of compatible donors, medical support raises ethical questions. These questions include the donor's personal freedom and possibly impaired free will to donate blood due to knowing they are the only compatible blood donor. This is further elucidated in the Discussion section.

\section{Materials and Methods}

Blood group typing was done using routine gel card matrix techniques (Micro Typing ID System, Bio-Rad Medical Diagnostic $\mathrm{GmbH}$, Cressier, Switzerland) including human ( $\mathrm{ABO} / \mathrm{Rh}$ and Rh-subgroups $+\mathrm{Cw}+\mathrm{K}$ ) and monoclonal antibodies (Diaclon $\mathrm{ABO} / \mathrm{RH}, \mathrm{ABO} / \mathrm{D}$ and Rh-subgroups $+\mathrm{K})$. DAT titer determination was done by tube method using polyvalent anti-human globulin (DiaClon Coombs-serum, Bio-Rad). Antibody screening with 3 test cells, antibody differentiation with 11 test cells, direct antiglobulin test (DAT), and antibody titers were performed in gel matrix (Micro Typing ID System, Bio-Rad Medical Diagnostic $\mathrm{GmbH}$ ). The indirect Coombs test included LISS/Coombs milieu with untreated cells as well as papainized test cells and $\mathrm{NaCl}$ gel cards with bromelain (Bio-Rad Medical Diagnostic GmbH). Antibody titers were performed against CCD.ee, ccD.EE and ccddee test cells (test cells from ID-DiaCell I-II-III, Bio-Rad Medical Diagnostic $\mathrm{GmbH}$ ).

Adsorption and elution studies were performed by adsorbing the patient's antibody using donor blood cells blood group $\mathrm{O}$ with the Rh subgroups CCD.ee, ccD.EE, and ccddee. Each eluate was tested against CCD.ee, ccD.EE and ccddee cells (test cells from IDDiaCell I-II-III, Bio-Rad Medical Diagnostic GmbH) respectively. Moreover, adsorption and elution was used for the confirmation of the absence of C, c, E, e antigens on maternal RBCs by using polyclonal anti-C (Molter, Neckargemünd, Germany), anti-c (BioRad Medical Diagnostic GmbH), anti-E (Bio-Rad Medical Diagnostic $\mathrm{GmbH}$ ), and anti-e (Molter).

DNA from maternal peripheral blood and cord blood from the fourth child were genotyped by SSP-PCRs (RBC Ready Gene CDE, Inno-Train Diagnostik GmbH, 61,476 Kronberg im Taunus, Germany), and the latter was additionally tested for RHD zygosity
(RBC Ready Gene ZygoFast, Inno-Train Diagnostik GmbH). DNA sequencing was performed as described $[6,7]$. D antigen density was measured by flow cytometry using 5 monoclonal antiD antibodies: Brad-3, P3×290, P3×241, P3×249, and ESD1 [6]. Additionally, the fetal middle cerebral artery peak systolic velocity (MCA-PSV) was investigated closely in both pregnancies.

\section{Results}

A 24-year-old woman was identified as -D- phenotype with anti-Rh 17 in routine serologic screening during her third pregnancy. She was typed O, C-c-D+E-e- and K-. The absence of C, c, E, and e antigens was confirmed by CDE PCR-SSP and by adsorption/elution studies with corresponding polyclonal sera. Sequence analysis identified no changes in $R H D$ exons $1-10$, indicating the presence of $R H D^{*} 01$, and, furthermore, resulted in $R H C E$ $D(3-9)-C E$. Antigen density measurement revealed an exalted expression of $\mathrm{D}$ antigen with 88.000 per erythrocyte. Antibody screening and differentiation initially appeared as a combination of anti-C and anti-e. However, by antibody adsorption using a ccD.EE RBC, the eluate contained a Ce antibody. Therefore, it was not a combination of 2 antibodies but rather a highly reactive anti-Rh17. The father of both children was typed O, C+c-D+E-e+ (R1R1), also confirmed by PCR-SSP. The DAT from the maternal blood was negative during both the fourth and fifth pregnancy.

The antibody was first detected during the third pregnancy when we received a blood sample from a community hospital. This pregnancy resulted in a spontaneous abortion. Prior to the miscarriage, the Iraqi woman had given birth to 2 children, of whom one had died soon after birth. The previous pregnancies had taken place in the country of origin of the family and no further information about the circumstances was available. The fourth pregnancy was the first one to be monitored at our tertiary care unit. From $26+1$ weeks of gestation (WGA) on, maternal antibody titers were assessed at 1- to 2-week intervals. Furthermore, MCA-PSV of the fetus was investigated closely. In that pregnancy, antibody titers did not increase (maximal antibody titer of 1:128) and no signs of fetal anemia were detected. The baby was born at $38+3$ WGA without complication. The newborn girl was typed as $\mathrm{O}, \mathrm{C}+\mathrm{c}-\mathrm{D}+\mathrm{E}-\mathrm{e}+,-\mathrm{D}-/ \mathrm{CD}$. The DAT of the cord blood was positive, with an antibody titer of 1:8 (tube method), but no additional treatment of the newborn was necessary (Table 1).

During the fifth pregnancy, antibody titers against CCD.ee, ccD.EE and ccddee were substantially higher than in the previous pregnancy. In the first analysis of the maternal serum at $8+4 \mathrm{WGA}$, the titers were 1:512 against CCD.ee, 1:256 against ccD.EE, and 1:512 against ccddee test cells. The highest titer determined was 1:4,096 
Table 1. The last and highest antibody titers of maternal serum of pregnancy 4 in 2017 and pregnancy 5 in 2019 before birth, the earliest titer of maternal serum and the titers of the cord blood serum of pregnancy 5 with 3 different test cells (CCD.ee, ccD.EE, and ccddee)

\begin{tabular}{|c|c|c|c|c|c|c|c|}
\hline & \multicolumn{3}{|c|}{ Fourth pregnancy (2017) } & \multicolumn{4}{|c|}{ Fifth pregnancy (2019) } \\
\hline & $\begin{array}{l}\text { maternal blood } \\
\text { of } 26+1 \text { WGA, } \\
\text { maximum titer }\end{array}$ & $\begin{array}{l}\text { maternal blood } \\
\text { of } 38+2 \text { WGA }\end{array}$ & $\begin{array}{l}\text { cord blood } \\
\text { (DAT 1:8) }\end{array}$ & $\begin{array}{l}\text { maternal blood } \\
\text { of } 8+4 \text { WGA }\end{array}$ & $\begin{array}{l}\text { maternal blood } \\
\text { of } 12+4 \text { WGA, } \\
\text { maximum titer }\end{array}$ & $\begin{array}{l}\text { maternal blood } \\
\text { of } 34+4 \text { WGA }\end{array}$ & $\begin{array}{l}\text { cord blood } \\
\text { (DAT 1:16) }\end{array}$ \\
\hline CCD.ee-titer & 128 & 64 & n.a. & 512 & 2,048 & 512 & 32 \\
\hline ccD.EE-titer & 32 & 8 & n.a. & 265 & 512 & 128 & Negative \\
\hline ccddee-titer & 128 & 32 & n.a. & 512 & 4,096 & 256 & 16 \\
\hline
\end{tabular}

WGA, weeks of gestation.

against ccddee test cells at $12+4$ WGA (Table 1). The phenomenon of weakened reactions with ccEE test cells might be explained by a different antigen density of Rh17 or could have been an interaction of Rh17 with the $\mathrm{RH}$ haplotype, comparable to the Ceppellini effect. Sonographic evaluations of the MCA-PSV revealed no signs of fetal anemia until $30+5$ WGA when MCA-PSV started to increase (Fig. 1). Since the frequency of CcEe negative donors is extremely low, we were prepared for potential transfusion requirements for both, i.e., the fetus/newborn and the mother. Only 1 compatible Austrian blood donor was already identified and informed to donate on demand. In case a blood transfusion would become necessary for the mother, we also provided a cryopreserved $-\mathrm{D}-\mathrm{RBC}$ unit. At $33+6 \mathrm{WGA}$, the sonographic criteria for fetal anemia (i.e., MCA-PSV > 1.5 multiples of the median, MoM) were fulfilled and fetal lung maturation was therefore administered. Follow-up examination at $34+3$ WGA revealed an MCA-PSV of $1.73 \mathrm{MoM}$, so cesarean section was scheduled and performed at $34+6$ WGA (Fig. 1). The newborn girl, weighing 1,980 g, had Apgar scores of 6, 9, and 9 at $1 \mathrm{~min}, 5 \mathrm{~min}$, and $10 \mathrm{~min}$, respectively. The cord blood hemoglobin ( $\mathrm{Hb})$ level was $8.5 \mathrm{mg} /$ $\mathrm{dL}$. Blood group typing from the cord blood revealed $\mathrm{O}$ -D-/CDe, a positive DAT of 1:16 (tube method) and the maternal anti-Rh17 antibody (titer 1:32 against CCD.ee, negative against ccD.EE and 1:16 against ccddee). Because of hyperbilirubinemia (maximum $10.9 \mathrm{mg} / \mathrm{dL}$ bilirubin at the age of 6 days), intensive blue phototherapy and intravenous immunoglobulin therapy $(4 \times 2,000 \mathrm{mg})$ were required. On days 5 and 11, a total of $65 \mathrm{~mL}$ of red blood cells from the $-\mathrm{D}$ - packed (p)RBCs from the only compatible donor identified in Austria (out of 8.9 million inhabitants) were administered. With the first dose of 25 $\mathrm{mL}$ on day $5, \mathrm{Hb}$ rose from 8.3 to $11.1 \mathrm{~g} / \mathrm{dL}$ and hematocrit rose from 22.9 to $30.3 \%$. The second dose, administered on day 11, increased $\mathrm{Hb}$ from 7.9 to $13.0 \mathrm{~g} / \mathrm{L}$ and hematocrit increased from 21.8 to $36.9 \%$. When the baby girl was 19 days old, she was discharged from hospital requiring further follow-up but no additional transfusions.

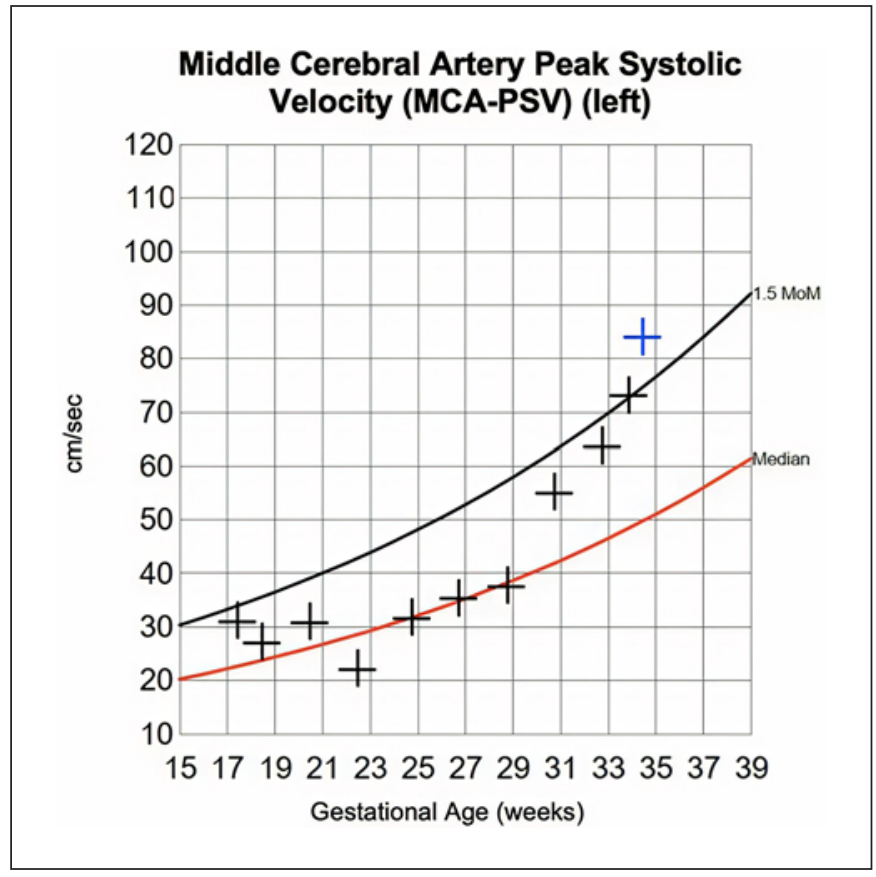

Fig. 1. Sonographic evaluations of the MCA-PSV during the fifth pregnancy: MCA-PSV of $1.73 \mathrm{MoM}$ at $34+3$ WGA. MoM, multiples of the median; WGA, weeks of gestation.

\section{Discussion}

The clinical importance of anti-Rh17 has been described as mild to severe $[2-5,8]$. We have described the course of the fourth and the fifth pregnancy of a woman with allo-anti-Rh17. As described by Shahverdi et al. [9] our patient also has a history of 2 unsuccessful pregnancies. In the fourth pregnancy, the already known antiRh17 did not induce HDFN. There were no signs of fetal anemia and the maternal antibody titer did not rise higher than 1:128. Although the cord blood showed a positive DAT, no further treatment of the newborn was necessary. Therefore, after the fourth pregnancy, the anti-Rh17 was considered benign. However, in the fifth pregnancy, the 
very first analysis at $8+4$ WGA showed titers 3-5 times higher than those at the end of pregnancy 4 . The pregnancy was observed closely and the baby was prematurely delivered by cesarean section at $34+6$ WGA because of sonographic signs of fetal anemia. After birth, the newborn received 2 pRBC concentrates, intensive blue phototherapy, and immunoglobulin 4 times. During the fifth pregnancy, antibody titers were considerably higher than in the previous pregnancy and postnatal transfusions were required as also described by Aref et al. [3]. Deitenbeck et al. [10] report successful pregnancies of a multipara where both intrauterine and postnatal transfusions were required. Whang et al. [11] and Denomme et al. [2] describe pregnancies of multipara with anti-Rh17 requiring intrauterine but no postnatal transfusions, in contrast to our case with hemolytic effects of anti-Rh17 becoming manifest after birth. An alternative therapy was suggested by Mimura et al. [12], who reported on a case of HDFN due to anti-Rh17 where the pregnant woman received multiple therapeutic plasma exchanges as well as highdose intravenous immunoglobulins. As a source of donor blood for intrauterine transfusions or transfusions of the newborn, maternal blood is suggested in the literature [2, $9,13,14]$. However, for our transfusion, we did not collect maternal blood because of the mother's low body weight [5]. We used allogenic blood from a compatible -D- donor, as also described by Hirose et al. [4] and Aref et al. [3]. As a second choice, in case the only compatible blood donor in Austria was not available, we would either have drawn a small amount of maternal blood or could have provided limited compatible or, respectively, the least incompatible $\mathrm{O}$ pos. CCee RBCs in order to avoid alloimmunization in the newborn. A similar procedure has been described by transfusion of ccEE RBCs to an infant with maternal anti-Rh17 [5]. Moreover, we allocated a cryopreserved -D- RBC unit for the planned cesarean section of the mother. With the expectation that any more pregnancies would be difficult and according to the potential will of the mother to prevent any further pregnancy, she was offered bilateral salpingectomy (as described in the literature [2]). However, she declined to undergo sterilization during cesarean section.

Following this case and the scarce literature on the topic, 2 points arise for further discussion: (1) the risk of hemolytic complications due to anti-Rh17 might increase with each pregnancy of a sensitized woman, and (2) blood supply in cases of rare blood groups and allo-antibodies against high-frequency antigens might lead to an ethical dilemma $[15,16]$. The ethical dilemma includes the voluntary nature of a blood donation and the protection of donors on the one hand, and the acute demand for blood to be donated on the other hand. There is limited availability of compatible blood, and the blood donation needs to be scheduled for right before the blood is urgently needed, so the donor's personal freedom might be restricted.

Although blood and blood components can be considered a public resource, nobody should be urged to donate blood for any reason. From a deontological, principlebased, ethical point of view, forced donations compromise human dignity by devaluating a person to a human resource and blood to personal property. The physical and physiological well-being and integrity of blood donors should be considered as an intrinsic value and the maintenance of this well-being and integrity as a duty in the debate about voluntariness. In contrast, teleological ethics, especially utilitarian ethics, strive for the greatest good for a maximum number of humans. Therefore, the consequence of blood donation and administration to a patient is of greater value as it is to increase the well-being of others (or a higher number). Although complications of blood donations are rare, there may be severe physical consequences to donating blood, e.g., infections, hematomas, incorrect venous puncture, or at least iron depletion [17-19]. In addition, forcing or straightforwardly asking someone with a rare blood group to donate blood might lead to emotional distress and a feeling of moral obligation. Moral coercion might arise and a truthful voluntariness of the donation can be compromised. In our opinion, the donor should be protected against any kind of moral coercion.

Upcoming approaches in supplying patients with compatible blood should be designed to leave options open for the donor so that a single donor does not have to be relied upon. Another concept for ensuring a supply of rare blood is further establishment of cryopreserved blood, either allogenic or autologous, or the application of autologous pRBCs when the recipient fulfills the donation criteria. Nevertheless, solidarity towards an individual person should be enhanced and appreciated, as it is a higher good that cannot and must not be forced. In conclusion, the potential for harm and benefit to both the donor and the recipient must be carefully taken into consideration.

\section{Acknowledgement}

We would like to thank Maria Stubenrauch, Karin Mallick, Katharina Sebauer, Anja Ulz, Elke Kohlmaier, and the immunohematological team for their technical assistance and helpful advice.

\section{Statement of Ethics}

This study was approved by the Medical University of Graz Ethics Committee (32-397 ex 19/20).
Torreiter et al. 


\section{Conflict of Interest Statement}

The authors declare that they have no conflicts of interest relevant to the manuscript.

\section{Funding Sources} ists.

The authors declare that no funding relevant to this paper ex-

\section{Author Contributions}

P.P.T. wrote the draft version of the paper, P.P.T., S.M., E.-M.M., P.S., T.W., G.F.K., M.S., and H.P. provided immunohematological data and analysis. B.R. added the pediatric part of the paper. P.K. contributed the obstetrical part of the paper. L.N. contributed to the part concerning ethics.

\section{References}

1 Daniels G. Human Blood Groups. 3rd ed. Wiley-Blackwell; 2013.

2 Denomme GA, Ryan G, Seaward PG, Kelly EN, Fernandes BJ. Maternal ABO-mismatched blood for intrauterine transfusion of severe hemolytic disease of the newborn due to anti-Rh17. Transfusion. 2004 Sep;44(9): 1357-60.

3 Aref K, Boctor FN, Pande S, Uehlinger J, Manning F, Eglowstein M, et al. Successful perinatal management of hydrops fetalis due to hemolytic disease associated with $\mathrm{D}$ - maternal phenotype. J Perinatol. 2002 Dec;22(8): 667-8.

4 Hirose M, Nakanishi K, Kaku S, Moro H, Hodohara K, Aotani H, et al. Fetal hemolytic disease due to anti-Rh17 alloimmunization. Fetal Diagn Ther. 2004 Mar-Apr;19(2):182-6.

5 Li BJ, Jiang YJ, Yuan F, Ye HX. Exchange transfusion of least incompatible blood for severe hemolytic disease of the newborn due to anti-Rh17. Transfus Med. 2010 Feb;20(1):66-

6 Matzhold EM, Polin H, Körmöczi GF, Macher S, Schönbacher M, Wagner T. RHD del28Phe (DMW) encoded by a novel in-frame deletion resulting in reduced $\mathrm{D}$ antigen expression. Transfusion. 2019 Sep;59(9):30334

7 Wagner FF, Ladewig B, Flegel WA. The RHCE allele ceRT: D epitope 6 expression does not require D-specific amino acids. Transfusion. 2003 Sep;43(9):1248-54.

8 Dajak S, Ipavec N, Cuk M, Golubic Cepulic B, Mratinovic-Mikulandra J, Milardovic J, et al. The Outcome of Hemolytic Disease of the Fetus and Newborn Caused by Anti-Rh17 Antibody: Analysis of Three Cases and Review of the Literature. Transfus Med Hemother. 2020 Jun;47(3):264-71.

9 Shahverdi E, Moghaddam M, Abolghasemi H. First report of the rare RhCE-depleted Dphenotype in sixteen people of Iranian origin. Vox Sang. 2019 Apr;114(3):256-61.

10 Deitenbeck R, Tutschek B, Crombach G, Stannigel H. Successful management of pregnancy and hemolytic disease of the newborn due to anti-HrO in a woman of the D-phenotype. Transfusion. 1999 Oct;39(10):1151-2.

11 Whang DH, Kim HC, Hur M, Choi JH, Park JS, Han KS. A successful delivery of a baby from a D-/D- mother with strong anti- Hr0. Immunohematology. 2000;16(3):112-4.

12 Mimura K, Endo M, Takahashi A, Doi Y, Sakuragi M, Kiyokawa T, et al. Successful management of fetal hemolytic disease due to strong anti-Rh17 with plasma exchange and intrauterine transfusion in a woman with the D-phenotype. Int J Hematol. 2020 Jan; 111(1):149-54.

13 Salamat N, Bhatti FA, Hussain A, Ziaullah. Anti-Rh17 (anti-Hr0): a rare diagnostic and management problem. J Pak Med Assoc. 2004 Apr;54(4):215-8.

14 Shah SI, Caprio M, Strauss R, Moskowitz N. Management of a full-term infant with hemolytic disease of the newborn due to an antiRh17 antibody in a mother with D- phenotype. Am J Hematol. 2005 Sep;80(1):88-9.

15 van den Burg PJ, Magnussen K. Ethical aspects of blood donors and the recipients of their blood. J Blood Transfus. 2012;2012: 606753.

16 Somerville MA. Ethical issues and challenges in implementing a new blood system. Transfus Med Rev. 1998 Jul;12(3):162-74.

17 Amrein K, Valentin A, Lanzer G, Drexler C. Adverse events and safety issues in blood donation-a comprehensive review. Blood Rev. 2012 Jan;26(1):33-42.

18 Drexler C, Macher S, Lindenau I, Holter M, Moritz M, Stojakovic T, et al. High-dose intravenous versus oral iron in blood donors with iron deficiency: the IronWoMan randomized, controlled clinical trial. Clin Nutr. 2020 Mar;39(3):737-45.

19 Macher S, Herster C, Holter M, Moritz M, Matzhold EM, Stojakovic T, et al. The Effect of Parenteral or Oral Iron Supplementation on Fatigue, Sleep, Quality of Life and Restless Legs Syndrome in Iron-Deficient Blood Donors: A Secondary Analysis of the IronWoMan RCT. Nutrients. 2020 May;12(5):E1313. 